\title{
Correction to: Optimisation of the Production and Bleaching Process \\ for a New Laccase from Madurella mycetomatis, Expressed in Pichia pastoris: from Secretion to Yielding Prominent
}

\author{
Ahmet Tülek ${ }^{1} \cdot$ Ersin Karataş $^{1} \cdot$ Mehmet Mervan Çakar $^{1} \cdot$ Derya Aydın $^{2} \cdot$ Özlem Yılmazcan $^{2} \cdot$ Barış Binay $^{3}$ (D)
}

Published online: 12 November 2020

(c) Springer Science+Business Media, LLC, part of Springer Nature 2020

\section{Correction to: Molecular Biotechnology}

https://doi.org/10.1007/s12033-020-00281-9

In the paper by "Tülek, A., Karataş, E., Çakar, M. M., Aydın, D., Y1lmazcan, Ö, Binay, B. (2020). Optimisation of the Production and Bleaching Process for a New Laccase from Madurella mycetomatis, Expressed in Pichia pastoris: from Secretion to Yielding Prominent Performance. Molecular Biotechnology, https://doi.org/10.1007/s12033-020-00281 $-9 "$.
We noted an error in the "Funding Information" section of the paper. We would like to clarify that we do not have any declaration of funding for this paper.

The original article has been corrected.

Publisher's Note Springer Nature remains neutral with regard to jurisdictional claims in published maps and institutional affiliations.
The original article can be found online at https://doi.org/10.1007/ s12033-020-00281-9.

Barış Binay

binay@gtu.edu.tr

Ahmet Tülek

a.tulek@gtu.edu.tr

Ersin Karataş

ekaratas@gtu.edu.tr

Mehmet Mervan Çakar

mcakar@gtu.edu.tr

Derya Aydin

Derya.Aydin@akkim.com.tr

Özlem Yılmazcan

Ozlem.Yilmazcan@akkim.com.tr

1 Department of Molecular Biology and Genetics, Gebze Technical University, 41400 Gebze, Kocaeli, Turkey

2 Ak-Kim Kimya San. Ve Tic. A.S., 77600 Çiftlikköy, Yalova, Turkey

3 Department of Bioengineering, Gebze Technical University, 41400 Gebze, Kocaeli, Turkey 